\title{
On the Grain Growth Kinetics of a Low Density Steel
}

\author{
Daniel M. Field ${ }^{(}$, Krista R. Limmer *(-) and Billy C. Hornbuckle
}

Weapons and Materials Research Directorate, US Army Combat Capabilities Development Command Army Research Laboratory, Aberdeen Proving Ground, MD 21005, USA

* Correspondence: krista.r.limmer.civ@mail.mil; Tel.: +1-410-306-2039

Received: 21 August 2019; Accepted: 6 September 2019; Published: 10 September 2019

check for updates

\begin{abstract}
The grain growth kinetics of an age-hardenable Fe-Mn-Al-C steel were investigated. Kinetics of grain growth were determined between 1173 and $1348 \mathrm{~K}\left(900-1075{ }^{\circ} \mathrm{C}\right)$ to obtain a range of grain sizes from 30 to $475 \mu \mathrm{m}$. It was found that grain growth was negligible at $1173 \mathrm{~K}\left(900{ }^{\circ} \mathrm{C}\right)$ for times up to $15 \mathrm{~h}$. The activation energy for grain growth was found to be $467 \mathrm{~kJ} / \mathrm{mol}$. The hardness and mean linear intercept (L3) were correlated to follow a traditional Hall-Petch relationship. Tensile properties of the alloy were determined after various solution treatments performed for $2 \mathrm{~h}$ followed by water quenching. Tensile strength increased from 810 to $960 \mathrm{MPa}$ and ductility was reduced from 80 to $60 \%$ as the grain size decreased from $200 \mu \mathrm{m}$ to $30 \mu \mathrm{m}$ as grain coarsening was mitigated by lowering the solution treatment temperature.
\end{abstract}

Keywords: grain growth; kinetics; austenitic steel; mechanical properties; low density steel

\section{Introduction}

\subsection{Low Density Steel}

Low density steels have become a topic of significant interest in both automotive and military applications for vehicle implementation [1-3]. These steels are derived from Robert Hadfield's original investigation of a Fe-13Mn-1.2C (in wt.\%) steel with elevated toughness, high work hardening, and optimal wear resistance [4]. The low density alloy steels are typically grouped into three types based on microstructures: Duplex, ferritic, or austenitic. The austenitic alloys, sometimes referred to as Fe-Mn-Al steels, are an attractive alloy system for automotive and cryogenic applications because of their high strength and formability as well as good low temperature toughness [1,5]. The density reduction of these alloys is typically attributed to the elevated additions of aluminum leading to a lattice dilation; with an aluminum content in the range of $5-11 \mathrm{wt} . \%$, a density reduction of about $15 \%$ can be obtained with equivalent toughness and strength as compared to conventional Cr-Mo steels in the quenched and tempered condition as reported by Bartlett and Van Aken [3]. The increased Al content $(>6 \mathrm{wt} . \%)$ has a secondary benefit for the austenitic alloys, age hardening by a low (720-920 K) temperature annealing process is a means to strengthen the steel $[3,6-8]$.

\subsection{Grain Size and Grain Growth}

Novel Mn steels targeting sheet or strip for the automotive market are processed by first hot rolling to gauges in the range of 2.5-3.0 mm and further cold rolled down to $1.0 \mathrm{~mm}$ [9-11] followed by some form of a recrystallization anneal $[9,12-15]$; this assists in refining the grain structure and producing alloys with grain sizes in the range of 0.5 to $5.5 \mu \mathrm{m}$ [9,12-15]. The work by Torabinejad et al. [11] investigated the effect of both cold rolling and temperature on the recrystallization time and grain size of a duplex TWIP steel annealed at 873 and $973 \mathrm{~K}\left(600\right.$ and $\left.700{ }^{\circ} \mathrm{C}\right)$ for varying times. It was shown that a fully recrystallized $\gamma$-austenite could be obtained when the alloy was cold worked $70 \%$ and annealed 
at $973 \mathrm{~K}\left(700^{\circ} \mathrm{C}\right)$ for $1 \mathrm{~h}$. The authors did not calculate the activation energy for grain growth after the recrystallized grains formed, but from their data an activation energy for grain growth of $134 \mathrm{~kJ} / \mathrm{mol}$ can be calculated.

Due to the single phase nature of the austenitic alloys however, grain size control can prove problematic. Much of the reported work has not targeted plate applications ( $>10 \mathrm{~mm})$, which cannot be processed using the traditional cold work and recrystallization processing to refine the grain structure. Furthermore, these alloys are typically solution treated at elevated temperature ( $>1173 \mathrm{~K})$ to homogenize the composition prior to age hardening precipitation, and the effect of this processing on the grain size can be deleterious to the properties of the steel by producing coarse grains and reducing the strength and toughness of the steel. There have been many works that investigated the effect of solution treatment temperature on the $\gamma$-austenite grain size $[12-14,16,17]$ and the effect of time at elevated temperature on grain size is summarized graphically in Figure 1. The data is shown in both a direct relationship of temperature vs. grain size (Figure 1a), and an Arrhenius-type plot (Figure 1b).
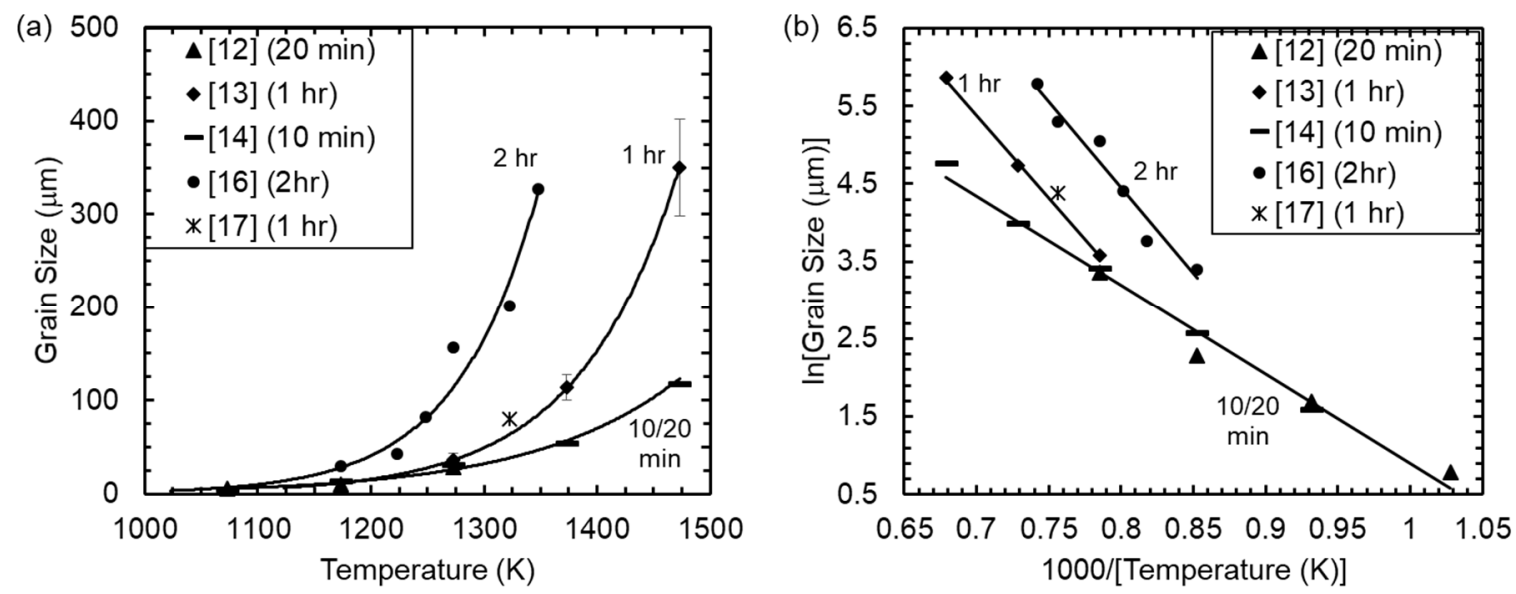

Figure 1. Grain size as a function of solution treatment temperature from references $[12-14,16,17]$ shown as (a) a direct relationship and (b) an Arrhenius relationship.

Yuan et al. [12] examined a Fe-25Mn-3Al-3Cr-0.3C-0.01N (in wt.\%) alloy that was cold rolled 83\% and solution annealed at varying temperatures for $20 \mathrm{~min}$ followed by water quenching. The measured grain sizes of the alloy were 2 to $30 \mu \mathrm{m}$ and as shown in Figure 1 with larger grain sizes measured for increasing solution treatment temperatures. Lee et al. [14] performed a similar experiment on a Fe-24Mn-4Cr-0.5C (in wt.\%) alloy as reported by Yuan; the steel was cold worked $\sim 60 \%$ and solution treated for $10 \mathrm{~min}$, and as can be seen in Figure 1 the data from Yuan et al.'s work is consistent with Lee et al. It is interesting to note the similarity between Yuan and Lee's results even with different annealing times, degree of cold work, and variation in composition. The work by Yoo et al. [13] however shows a deviation in grain size from both Yuan's and Lee's work at the higher temperatures. Yoo investigated a Fe-28Mn-10Al-1.0C (in wt.\%) steel cold rolled 65\% and solution treated at a range of temperatures for $1 \mathrm{~h}$, followed by water quenching, this deviation is however not surprising due to the increased time at temperature. The alloy reported by Moon et al. [17] was in the hot rolled condition, without cold rolling, however after solution treating for $1 \mathrm{~h}$ at $1323 \mathrm{~K}\left(1050{ }^{\circ} \mathrm{C}\right)$ the grain size is consistent with that reported by Yoo et al. [13], which was also annealed for $1 \mathrm{~h}$. The work by Field and Limmer [16] deviates further from the data discussed, however this alloy was not cold worked and solution annealing was performed for $2 \mathrm{~h}$ followed by water quenching. The deviation in the developed grain sizes appears to be most strongly correlated to the time at elevated temperature and also illustrates the significance in understanding the effect of processing (cold worked vs. hot rolled product), time, and temperature on the as-solutionized austenite grain structure.

Some work has been performed to understand the effect of alloying elements on the grain boundary mobility and quantify if certain elements produce a solute drag effect during solution 
treatment. Yoo et al. [18] determined the grain size of a Fe-28Mn-9Al-0.8C steel after varying solution treatment times and temperatures, but only reported the grain size after solution treating at $1273 \mathrm{~K}$ $\left(1000^{\circ} \mathrm{C}\right)$. A grain boundary mobility was not calculated by Yoo et al. but from their data the authors of this work determined it to be $1515 \frac{\mu m^{4}}{J * h r}$. Bhattacharyya et al. [19] investigated the effect of Mn and C on the grain growth kinetics of steel. The Mn content ranged from 5 to $30 \mathrm{wt} . \%$ and carbon was varied at either 0 or $0.5 \mathrm{wt} . \%$ Grain growth was studied comprehensively at $1473 \mathrm{~K}\left(1200^{\circ} \mathrm{C}\right)$ and some tests were performed at $1373 \mathrm{~K}\left(1100{ }^{\circ} \mathrm{C}\right)$ but were not discussed completely throughout the work. They concluded that the mobility of the grain boundaries was at a minimum for a Mn content of $15 \mathrm{wt} . \%$ Bhattacharyya also shows that the minimum associated with $15 \mathrm{wt} \% \mathrm{Mn}$ is correlated to the stacking fault energy (SFE) and twin boundary formation. It is interesting to note that the value of $15 \mathrm{wt} . \% \mathrm{Mn}$ is of secondary significance, it was found by Medvedeva et al. [20] that there exists a minimum in the SFE of fcc iron at $12 \mathrm{wt}$ \% Mn from first principles calculations. This result was also corroborated experimentally from the work of Pisarik and Van Aken [21] and Field et al. [22] who also showed there was a significant change in the martensite kinetics at $12 \mathrm{wt} \% \mathrm{Mn}$. These works are in close agreement with the Mn concentration at which there is a shift in grain boundary mobility as reported by Bhattacharyya et al. [19] A secondary work by Medvedeva et al. [23] showed by first principles that $\mathrm{Mn}$ and $\mathrm{C}$ will form a dipole in both bcc and fcc iron. According to Medvedeva et al. the formed dipole will partially offset the increase in SFE associated with carbon. Bhattacharyya et al. [19] showed a reduction in the grain boundary mobility for a $30 \mathrm{wt}$ \% Mn alloy with $0.5 \mathrm{wt}$ \% C compared to a carbon free $30 \mathrm{wt}$ \% Mn alloy. They argued that carbon reduced the mobility of grain boundaries only in their $30 \mathrm{Mn}$ alloy due to a measured increase in twin boundary frequency and this was due to an increase in SFE, which is in agreement with the first principles calculations.

\subsection{Mechanical Behavior}

Yoo et al. [18] investigated the effect of grain size on the mechanical properties of an as-solution treated steel. They varied the temperatures from 973 to $1273 \mathrm{~K}\left(700\right.$ to $\left.1000{ }^{\circ} \mathrm{C}\right)$, and showed that the best strength-ductility combination occurred for the largest grain size. This effect was attributed to the work hardening capacity of the steel; as the grain size increased from 5 to $38 \mu \mathrm{m}$ the work hardening rate reached a consistent maximum $(\sim 2000 \mathrm{MPa})$ however the coarsest grained sample obtained the maximum in work hardening at a higher strain level leading to greater total elongation and a better total performance of the steel as measured by the product of ultimate strength and total ductility. The purpose of this work is to quantify the grain growth kinetics of a Fe-Mn-Al-C and relate these kinetics to previous works. Secondarily to this, the effect of grain size on mechanical properties in the as-solution treated condition will be explored.

\section{Experimental Procedure}

A lightweight steel with a composition of Fe-30.8Mn-9.2Al-0.7Si-1.0C-0.5Mo (in wt.\%) was commercially cast into a $5450 \mathrm{~kg}$ ingot by Elwood Quality Steels. The SFE of the alloy was calculated to be $89 \mathrm{~mJ} / \mathrm{m}^{2}$ using a regular solution model according to the work of Pisarik and Van Aken [21]. After cooling the ingot was forged, and the forged slab was reheated and rolled by ArcelorMittal to a plate thickness of $12.7 \mathrm{~mm}$ to obtain a total thickness reduction of $95 \%$. The composition of the steel was confirmed using inductively couple plasma optical emission spectroscopy (ICP-OES) (Luvak Inc., Boylston MA, USA) after dissolution in nitric acid and the carbon content was determined using gas combustion analysis.

Samples for solution treatment were placed in stainless steel bags, to minimize decarburization and oxidation, and heated to the solution treating temperature for $0.5-15 \mathrm{~h}$ followed by water quenching to room temperature. The temperature of the sample was tracked using an external thermocouple and treatment time was based upon surface temperature obtaining the targeted solution treatment value; heating rates to the targeted solution treat temperature ranged from 30 to $35 \mathrm{~K} / \mathrm{min}$. Grain size analysis was performed in the transverse plane (perpendicular to both the normal direction and rolling 
direction). Samples were mechanically polished to $0.02 \mu \mathrm{m}$ with colloidal silica solution and etched with $10 \%$ nital solution of nitric acid and methanol. Scanning electron microscopy (SEM) images were taken with a Phenom XL (Thermo Fisher Scientific, Waltham, MA, USA) operating at $15 \mathrm{kV}$ using the backscatter mode. Grain size values were determined using ASTM E112 [24] line method considering only grain boundaries. The mean linear intercept value (L3) was measured according to ASTM E112 using the Heyn Lineal Intercept method and included twin boundaries. Specimens for electron backscattered diffraction (EBSD) were observed prior to etching. Orientation image mapping via pattern analysis was performed on an FEI NanoSEM (Thermo Fisher Scientific, Waltham, MA, USA) operated at an accelerating voltage of $20.0 \mathrm{kV}$ and an emission current of $2.7 \mathrm{nA}$.

Hardness was measured by Rockwell C and B techniques and converted to Brinell hardness (HBW) for reporting according to ASTM E18-17 [25]. A standard ASTM E8 [26] tensile bar with a gauge length of $50 \mathrm{~mm}$ and gauge width of $12.5 \mathrm{~mm}$ was water-jet cut parallel to the rolling direction and the gauge edge was sanded to remove chatter marks from water-jet cutting. Gauge surfaces were ground to remove any surface oxide and decarburization from hot rolling and heat treatment. Strain was measured using digital image correlation (DIC) and tests were performed in displacement control at a rate of $0.02 \mathrm{~mm} / \mathrm{sec}$ using a $250 \mathrm{kN}$ load cell on an Instron model 5989 frame (Instron Co., Norwood, MA, USA).

\section{Results}

Grain sizes $\left(D_{f}\right)$ of the annealed alloy are shown in Figure 2a. Mobility values were determined from the change in grain diameter squared as derived by the works of Hillert [27] and Burke and Turnbull [28] and are shown in Figure 2b, with the tabulated mobility (M) values shown in Table 1. The mobility of grain boundaries is modeled according to Equation (1). It should be noted in the grain surface mobility at $1173 \mathrm{~K}\left(900^{\circ} \mathrm{C}\right)$ the $\mathrm{R}^{2}$ value shows the poorest fit to the data. Tabulated values of the grain sizes, hardness, and their standard deviations are given in greater detail in Table A1. A set of representative backscattered electron (BSE) images are shown for annealing at $1173 \mathrm{~K}\left(900{ }^{\circ} \mathrm{C}\right)$ for $0.5 \mathrm{~h}$ (Figure $3 \mathrm{a}$ ) and $4 \mathrm{~h}$ (Figure $3 \mathrm{~b}$ ) showing negligible grain size change and for annealing at $1348 \mathrm{~K}$ $\left(1075^{\circ} \mathrm{C}\right.$ ) for $0.5 \mathrm{~h}$ (Figure $3 \mathrm{c}$ ) and $4 \mathrm{~h}$ (Figure $3 \mathrm{~d}$ ) showing a significant increase in the grain size from $110 \mu \mathrm{m}$ to $250 \mu \mathrm{m}$.

$$
D_{f}^{2}-D_{0}^{2}=M t
$$

where $M$ is the grain boundary mobility, $D_{f}$ is the grain size after annealing, $D_{0}$ is the initial grain size, and $t$ is the time in hours.
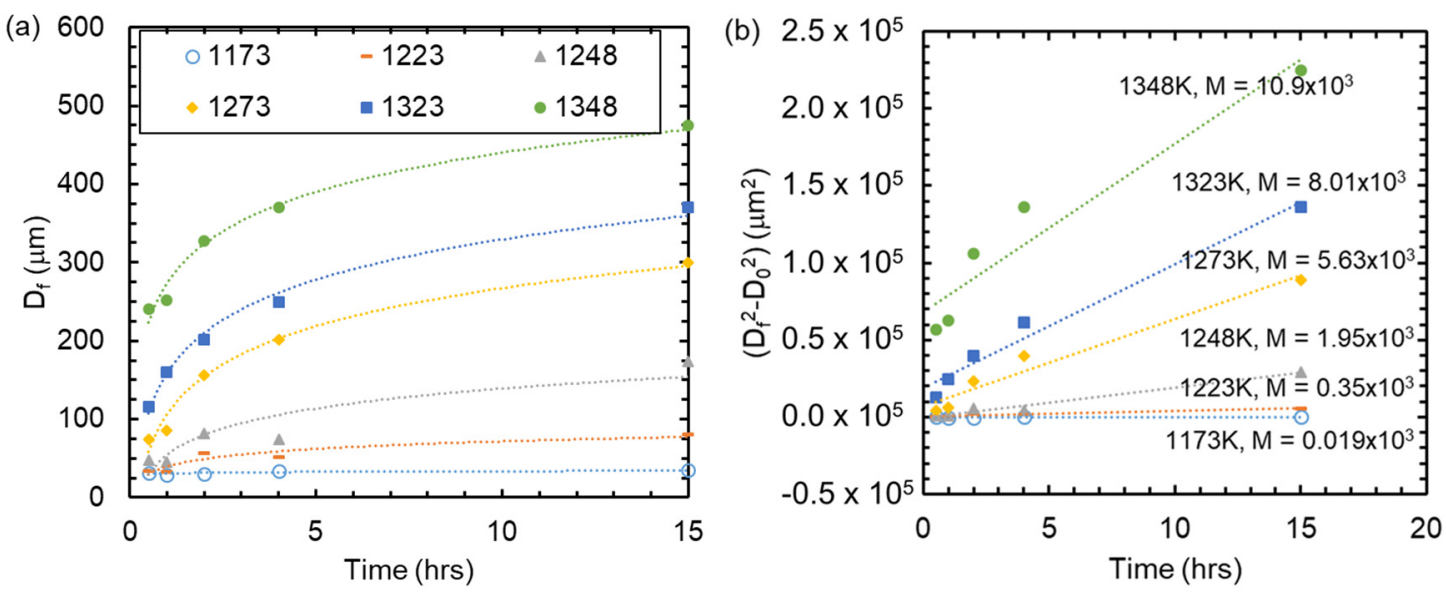

Figure 2. (a) $\gamma$-austenite grain size as a function of annealing time and temperature illustrating parabolic response. (b) Mobility calculation to obtain the growth rate as a function of annealing time according to Equation (1). 

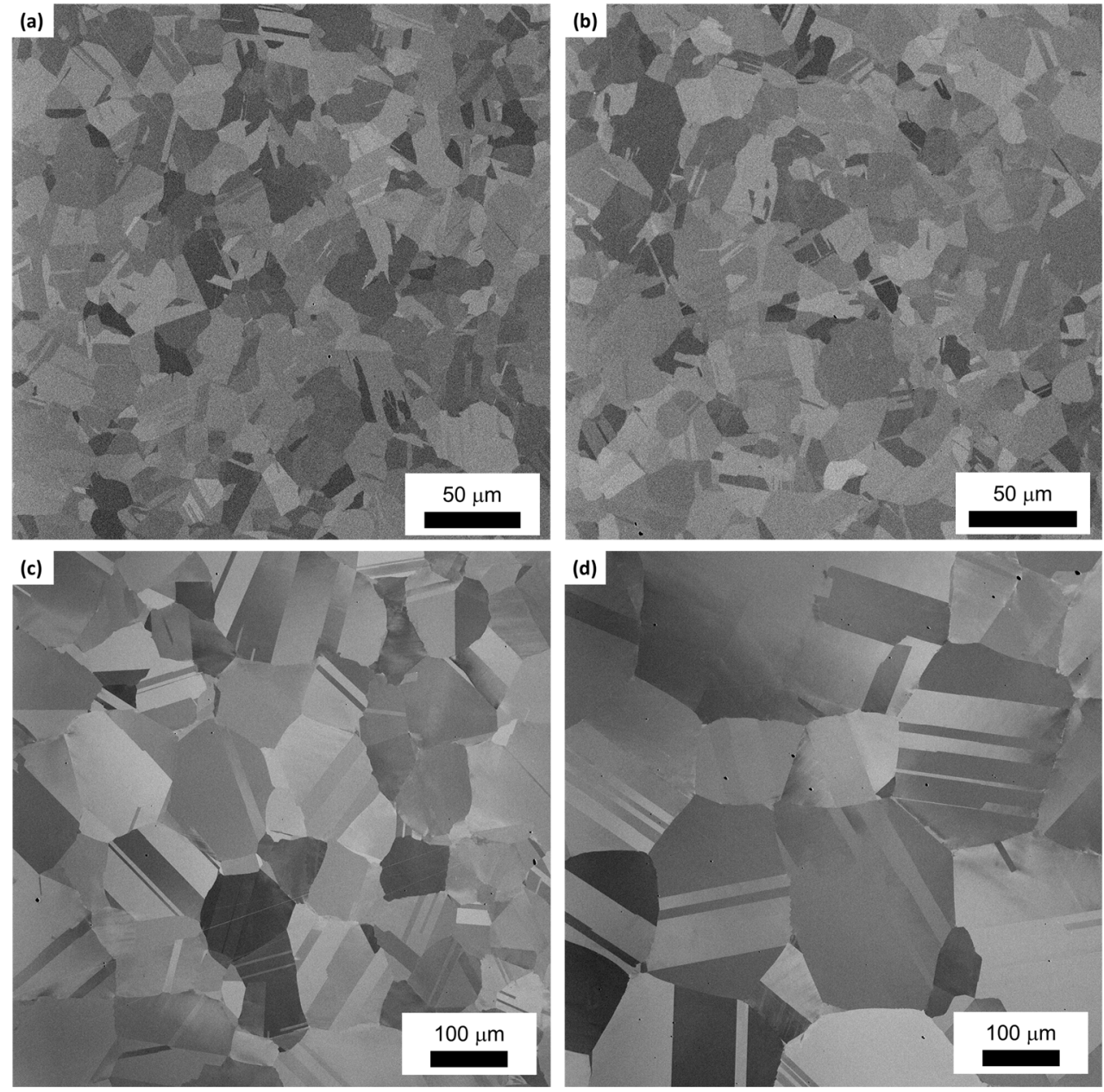

Figure 3. Representative images of samples solution annealed at $1173 \mathrm{~K}\left(900^{\circ} \mathrm{C}\right)$ for $(\mathbf{a}) 0.5 \mathrm{~h}$ and $(\mathbf{b}) 4 \mathrm{~h}$ and annealed at $1348 \mathrm{~K}\left(1075^{\circ} \mathrm{C}\right)$ for (c) $0.5 \mathrm{~h}$ and (d) $4 \mathrm{~h}$.

Table 1. Mobility (M) values for the lightweight steel at varying annealing temperatures, with least squares fit $\left(\mathrm{R}^{2}\right)$ shown for reference.

\begin{tabular}{ccc}
\hline Annealing Temperature & Mobility $\frac{\mu m^{4}}{J^{*} h r}(\mathbf{M})$ & $\mathbf{R}^{2}$ Value \\
\hline $1173 \mathrm{~K}\left(900^{\circ} \mathrm{C}\right)$ & $0.194 \times 10^{2}$ & 0.588 \\
$1223 \mathrm{~K}\left(950^{\circ} \mathrm{C}\right)$ & $0.350 \times 10^{3}$ & 0.898 \\
$1248 \mathrm{~K}\left(975^{\circ} \mathrm{C}\right)$ & $1.95 \times 10^{3}$ & 0.975 \\
$1273 \mathrm{~K}\left(1000^{\circ} \mathrm{C}\right)$ & $5.63 \times 10^{3}$ & 0.957 \\
$1323 \mathrm{~K}\left(1050^{\circ} \mathrm{C}\right)$ & $8.01 \times 10^{3}$ & 0.973 \\
$1348 \mathrm{~K}\left(1075^{\circ} \mathrm{C}\right)$ & $10.9 \times 10^{3}$ & 0.922 \\
\hline
\end{tabular}

From the mobility data shown in Figure 2 and Table 1 an activation energy is calculated according to the typical Arrhenius relationship as calculated according to Equation (2). The activation energy $(\mathrm{Q})$ calculated for grain growth in this Fe-30.8Mn-9.2Al-0.7Si-1.0C-0.5Mo system is $467 \mathrm{~kJ} / \mathrm{mol}$ as shown in Figure 4. The calculated mobility from Yoo et al. [18] for a Fe-28Mn-9Al-0.8C alloy is also included for reference and it is noted that the data is consistent to what was produced in this work. A Hall-Petch grain size (or mean free path) dependence for hardness is graphed in Figure 5 for the solution treated and quenched material. It should be noted that twin boundaries were included when considering the 
mean free path and showed the best correlation to the hardness data. A grain boundary hardening term $(k)$ of $445 \mathrm{HBW} \cdot \sqrt{ } \mu \mathrm{m}$ and a friction stress of $175 \mathrm{HBW}$ is obtained for the alloy under investigation.

$$
M=k_{0} \exp \left(-\frac{Q}{R T}\right)
$$

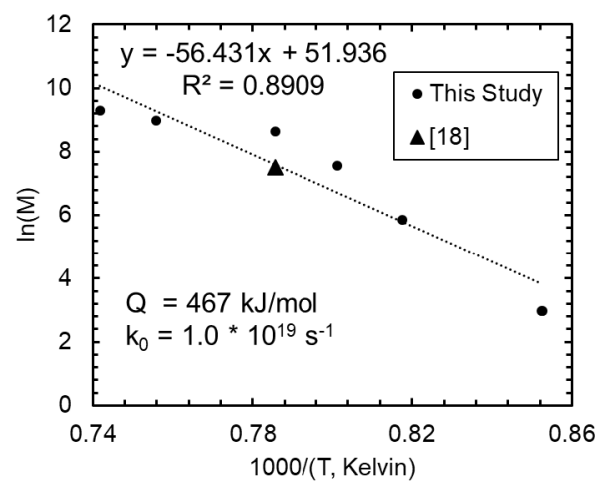

Figure 4. Determination of the activation energy (Q) for grain growth, a $Q$ value of $467 \mathrm{~kJ} / \mathrm{mol}$ is calculated for this alloy.

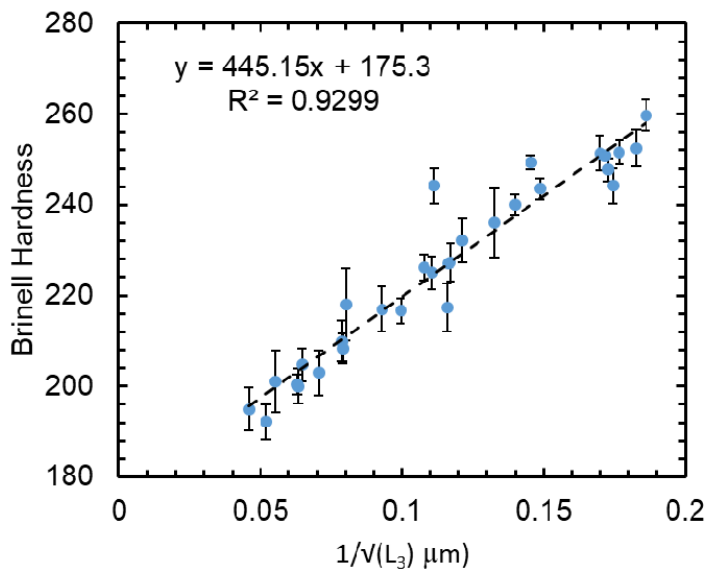

Figure 5. Hall-Petch relationship for the Fe-Mn-Al alloy after annealing to obtain various mean linear intercept values (L3).

A stress-strain plot of the steel in the as-solution treated two hour condition, is shown in Figure 6a. The work hardening rate of the tested steel is calculated in Figure $6 \mathrm{~b}$ and a summary of the tensile properties are listed in Table 2. The work hardening rate for the 1173 and $1223 \mathrm{~K}\left(900\right.$ and $\left.950{ }^{\circ} \mathrm{C}\right)$ solution treated material obtains the highest maximum of $2200 \mathrm{MPa}$ early at the onset of plastic deformation after the material has yielded, during further deformation the material's work-hardening response is decreased until the alloy necks and fractures. The 1273 and $1323 \mathrm{~K}\left(1000\right.$ and $\left.1050{ }^{\circ} \mathrm{C}\right)$ conditions exhibit a slightly different behavior, the maximum in the work-hardening is not observed until a later stage of deformation at roughly 0.3 true strain and a lower maximum is obtained, $1970 \mathrm{MPa}$. The elastic modulus of the alloy is noted to be $155 \pm 6 \mathrm{GPa}$, which is significantly lower than typical Fe-C steels and is typically attributed to the effect of increased $\mathrm{Al}$ and $\mathrm{Mn}$ on causing solid solution softening as reported in literature by both Bartlett and Van Aken [3] and Field et al. [22] for manganese steels. 

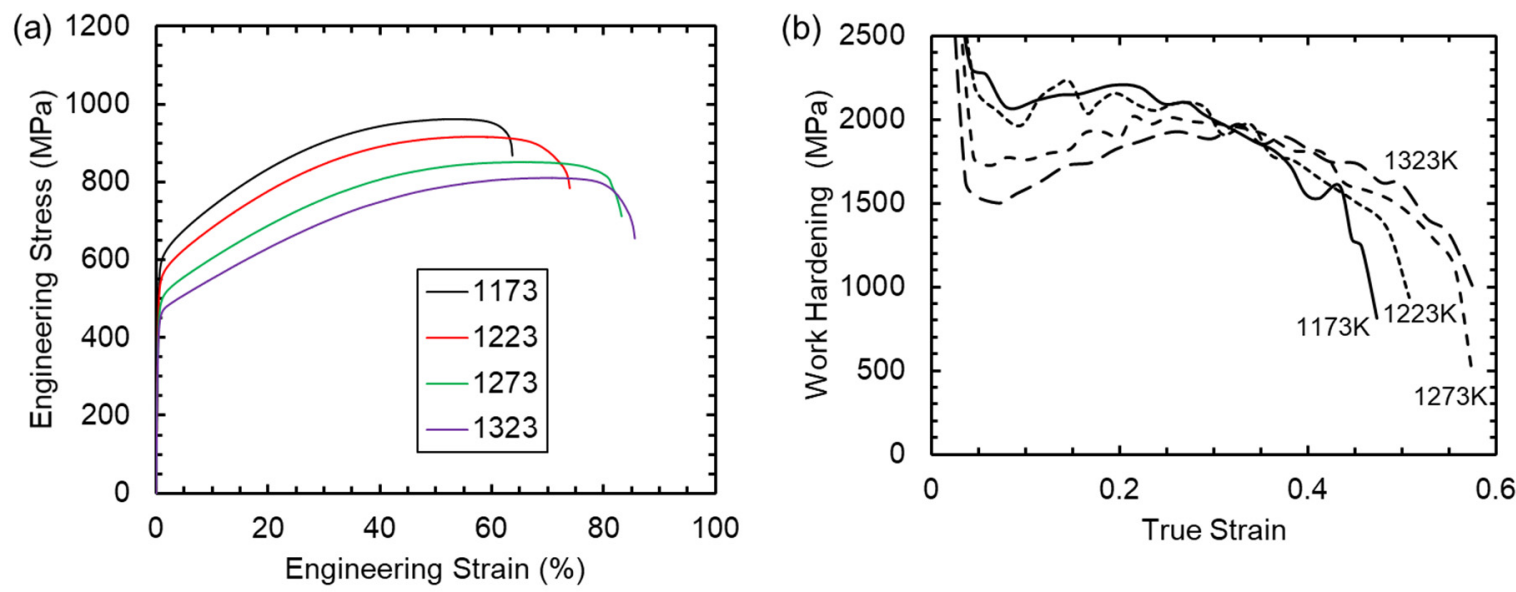

Figure 6. Representative mechanical properties of the steel: (a) Engineering stress-strain curves after solution treatment and (b) instantaneous work hardening coefficient for the as-solution treated alloy.

Table 2. Mechanical properties of the two hour solution treated samples.

\begin{tabular}{ccccccc}
\hline Condition & $\begin{array}{c}\text { Hardness } \\
(\mathbf{H B W})\end{array}$ & $\begin{array}{c}\text { Grain Size } \\
(\boldsymbol{\mu} \mathbf{m})\end{array}$ & $\begin{array}{c}\text { Modulus } \\
(\mathbf{G P a})\end{array}$ & $\begin{array}{c}\text { Yield Strength } \\
(\mathbf{M P a})\end{array}$ & $\begin{array}{c}\text { Ultimate } \\
\text { Strength (MPa) }\end{array}$ & $\begin{array}{c}\text { Total } \\
\text { Elongation (\%) }\end{array}$ \\
\hline $1173 \mathrm{~K}$ & $245 \pm 7$ & $30 \pm 2$ & $155 \pm 3$ & $555 \pm 7$ & $957 \pm 7$ & $63 \pm 1$ \\
$1223 \mathrm{~K}$ & $236 \pm 9$ & $57 \pm 8$ & $154 \pm 3$ & $505 \pm 1$ & $919 \pm 4$ & $72 \pm 2$ \\
$1273 \mathrm{~K}$ & $224 \pm 3$ & $156 \pm 6$ & $152 \pm 5$ & $440 \pm 2$ & $851 \pm 13$ & $83 \pm 4$ \\
$1323 \mathrm{~K}$ & $201 \pm 2$ & $201 \pm 8$ & $155 \pm 6$ & $410 \pm 6$ & $811 \pm 4$ & $86 \pm 7$ \\
\hline
\end{tabular}

Representative EBSD orientation image maps (OIM) of the tensile tested samples in the as-solution treated condition is shown in Figure 7. It is noted that the alloy does not undergo deformation twinning due to its very high SFE. The deformation mechanism appears to be a planar slip as reported for alloys with high SFE.
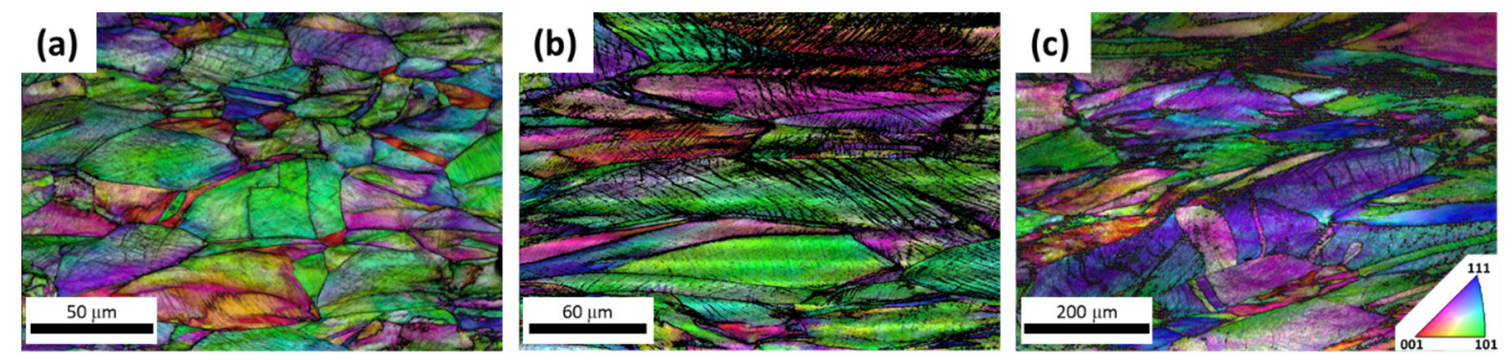

Figure 7. EBSD-OIM maps of the tensile tested alloy solution treated for two hours at (a) $1223 \mathrm{~K}$ $\left(950^{\circ} \mathrm{C}\right),(\mathbf{b}) 1273 \mathrm{~K}\left(1000^{\circ} \mathrm{C}\right)$, and $(\mathbf{c}) 1323 \mathrm{~K}\left(1050^{\circ} \mathrm{C}\right)$. The loading axis was in the horizontal direction.

\section{Discussion}

\subsection{Grain Growth}

The activation energy for grain growth determined using an Arrhenius relationship using experimental data was found to be $467 \mathrm{~kJ} / \mathrm{mol}$. There has been no reported activation energy for grain growth in the Fe-Mn-Al lightweight alloys to date and no direct comparison can be made with respect to the activation energy for grain growth in these highly alloyed systems. The alloy investigated by Torabinejad et al. [11] exhibited an activation for grain growth of $134 \mathrm{~kJ} / \mathrm{mol}$, which is significantly lower that what is shown in this work. The amount of cold work in the systems investigated by Torabinejad was 40 and $60 \%$ and it is expected that this would accelerate recrystallization and grain growth with increased sites for recrystallization available. Further, the Torabinejad alloy was reported 
to be comprised of a duplex $\delta$-ferrite $+\gamma$-austenite microstructure; although it has been reported that in the case of these duplex steels it is possible to obtain conditions where the two phases recrystallize independently $[29,30]$ it is non-trivial to determine the kinetics for both recrystallization and grain growth. It should be realized that the temperature regime Torabinejad investigated was 873 and $973 \mathrm{~K}$ $\left(600\right.$ and $\left.700{ }^{\circ} \mathrm{C}\right)$ and it has been documented by the work of Lücke and Detert [31], and Gordon and Vandermeer [32] that the activation energy will increase as the temperature is increased due to a shift in the rate controlling step. As such the work from Torabinejad appears to show that the grain growth is influenced by the diffusion of carbon in the $\gamma$-austenite which has also been reported to be $134 \mathrm{~kJ} / \mathrm{mol}$ [33].

Previous work on low alloy steels can provide a measure for what components are responsible for the high activation energy determined in this study. A grain growth examination of six SAE grades: 1045, 4140, 4340, 8620, 9310, and 52,100 was done by Khzouz [34], the reported compositions and the activation energy for grain growth are summarized in Table 3. It can be seen that the highest activation energy for grain growth is associated with the highest carbon content. This is also in agreement with the work by Lee and Lee [35] who characterized and quantified the effects of C, Ni, Cr, and Mo on the grain growth activation energy of low alloy steels. They showed that carbon $(3.58 \mathrm{~kJ} / \mathrm{mol}$ per wt. $\%$ addition) and molybdenum ( $4.03 \mathrm{~kJ} / \mathrm{mol}$ per $\mathrm{wt} . \%$ addition) had the greatest effect on increasing the activation energy, however the effects of $\mathrm{Si}$ and $\mathrm{Mn}$ were held constant and not addressed in their work. It is also of utility to compare the grain growth activation energy of the Fe-Mn-Al alloy in this study to an austenitic stainless steel due to the similarity in the microstructure and the high alloy content. Kashyap and Tangri [36] report the activation energy for a 316L stainless steel to be $317 \mathrm{~kJ} / \mathrm{mol}$ for a similar temperature range, and it can be rationalized that the reduced carbon $(<0.08 \mathrm{wt}$. $\%)$ content of a $316 \mathrm{~L}$ would also be consistent with the reduced activation energy as compared to the Fe-Mn-Al alloy in this study which has 1.00 wt.\% carbon.

Table 3. Reported alloys and their measured activation energy for grain growth.

\begin{tabular}{|c|c|c|c|c|c|c|c|c|}
\hline \multirow{2}{*}{ Alloy } & \multicolumn{7}{|c|}{ Element in wt.\% } & \multirow{2}{*}{$\underset{(\mathrm{kJ} / \mathrm{mol})}{\mathrm{Q}}$} \\
\hline & $\mathrm{C}$ & $\mathrm{Cr}$ & Mn & Mo & $\mathrm{Ni}$ & Al & Si & \\
\hline 1045 [34] & 0.48 & 0.12 & 0.75 & 0.02 & 0.08 & - & 0.215 & 253 \\
\hline $4140[34]$ & 0.38 & 1.03 & 0.70 & 0.15 & 0.16 & - & 0.23 & 175 \\
\hline $4340[34]$ & 0.42 & 0.80 & 0.80 & 0.23 & 1.07 & - & 0.24 & 213 \\
\hline 8620 [34] & 0.21 & 0.56 & 0.81 & 0.15 & 0.45 & - & 0.24 & 288 \\
\hline $9310[34]$ & 0.12 & 1.3 & 0.61 & 0.14 & 3.49 & - & 0.24 & 273 \\
\hline $52100[34]$ & 0.98 & 1.57 & 0.32 & 0.03 & 0.10 & - & 0.2 & 353 \\
\hline 316L [36] & 0.03 & 17.0 & 2.0 & 2.5 & 12.0 & - & 0.75 & 317 \\
\hline This Study & 1.00 & 0.12 & 30.8 & 0.5 & 0.10 & 9.2 & 0.7 & 467 \\
\hline
\end{tabular}

Bhattacharyya et al. [19] examined the effect of Mn and C on grain boundary mobility for Mn concentrations from 0 to $30 \mathrm{wt}$.\%. They state that a reduction of carbon decreases the grain boundary mobility in high manganese steels. Bhattacharyya et al. [19] stated that the mobility is decreased as the Mn concentration is increased up to $15 \mathrm{wt} \%\left(-9.0 \times 10^{-12} \frac{\mu m^{4}}{J * h r}\right.$ per wt.\% Mn) and from 15 to $30 \mathrm{wt}$. pct the mobility exhibits a slight increase with increasing Mn concentration $\left(1.4 \times 10^{-13} \frac{\mu m^{4}}{J * h r}\right.$ per wt.\% Mn). They also state that carbon increases the grain boundary mobility by altering the morphology of twin boundaries, which is consistent with the seminal work by Charnock and Nutting [37] who correlated the SFE to twin interface, however because they do not calculate the SFE these effects are not fully explained. The grain boundary mobility calculated for $1473 \mathrm{~K}\left(1200^{\circ} \mathrm{C}\right)$ from this study and previously reported works $[18,37,38]$ are shown in Figure 8 as a function of SFE. As can be seen in Figure 8 an increase in SFE leads to an increase in the grain boundary mobility. This implies that alloying elements like $\mathrm{C}$ and $\mathrm{Al}$, which are strong SFE increasing components, will also increase the grain boundary mobility. It is important to note that the values being compared are the grain boundary mobilities at a 
fixed temperature. While these values show a trend such that an increase in SFE leads to an increase in total boundary mobility these are not the grain growth activation energies and cannot be determined from reported values. It should be realized that the value of activation energy alone will not model the kinetics of grain growth and the pre-exponential term $\left(k_{0}\right)$ is also required and data on these values are rarely reported in literature. This further stresses the need for better investigation into the kinetics of grain growth for these novel alloys with high solute contents to accurately predict the grain size and define optimum processing parameters. This furthermore illustrates the need for better understanding of the effect of alloying elements on not only the solute drag but the total energy required for grain growth. It should also be noted that in the experimental work of Bhattacharyya et al. [19] utilizing atom probe tomography, carbon was found to segregate to the grain boundaries which would imply an energy cost associated with $\mathrm{C}$ and grain growth. This result is also in agreement to previous works which showed that interstitial atoms can sit at grain boundaries altering the grain boundary energy and increases the total energy required for grain boundary motion activation.

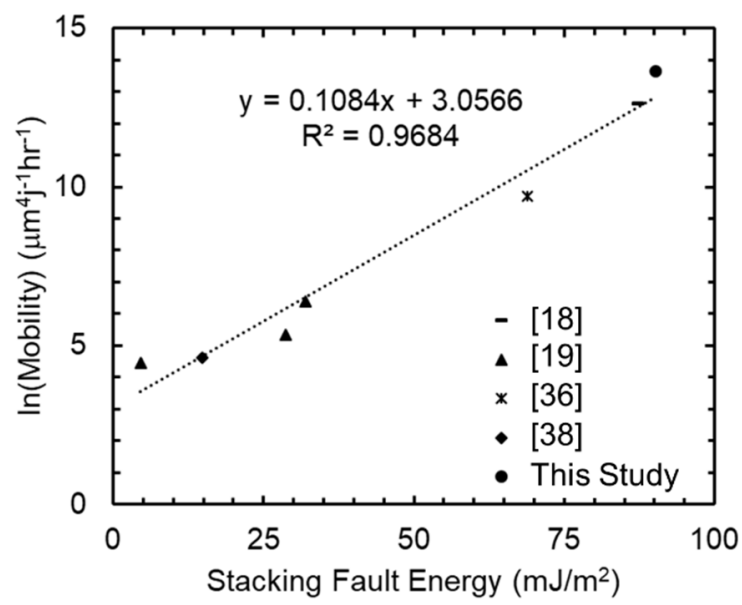

Figure 8. Effect of stacking fault energy on the grain boundary mobility calculated at $1473 \mathrm{~K}\left(1200^{\circ} \mathrm{C}\right)$ of the alloy under investigation and previously reported Mn steels.

\subsection{Mechanical Properties}

The effect of grain size on mechanical properties can be observed in both the hardness (Figure 5) and quasi-static tensile (Table 2) results. In the as-solution treated condition the maximum work hardening rate $(2200 \mathrm{MPa})$ is obtained in the 1173 and $1223 \mathrm{~K}\left(900\right.$ and $\left.950{ }^{\circ} \mathrm{C}\right)$ samples with L3 values of 30 and $57 \mu \mathrm{m}$ respectively. This is consistent with the work presented by Yoo et al. [18] who reports a similar maximum work hardening of $\sim 2000 \mathrm{MPa}$ for a similar grain size. The ultimate strength, as the grain structure coarsened, dropped from $950 \mathrm{MPa}$ to $810 \mathrm{MPa}$ in the $1323 \mathrm{~K}\left(1050{ }^{\circ} \mathrm{C}\right)$ condition as well as the maximum work hardening rate which is reduced to $1970 \mathrm{MPa}$. The effect of grain size on the work hardening capacity of metallic materials is well documented and it has been shown that as the grain size is reduced the work hardening capacity is increased. This effect is typically explained as due to the boundary hardening term from the Hall-Petch analysis as expressed in Figure 5 shown to be $445 \mathrm{HBW} \cdot \mu \mathrm{m}^{-1 / 2}$ and is consistent to previously reported works of high Mn Fe-Mn-Al steels [16,18]. It is also noted that as the grain size decreases the total ductility of the alloy is decreased, and this is also a typical response for metallic materials. It should be noted however, all of the conditions tested in the as-solution treated condition had elongations greater than $60 \%$ and it is expected that all of these conditions remain highly formable. Work reported by Field and Limmer also showed in age-hardened Fe-Mn-Al alloys that as the grain size is reduced below $80 \mu \mathrm{m}$ the toughness can be increased by up to $25 \mathrm{~J}$ as measured by charpy v-notch toughness testing at $298 \mathrm{~K}\left(25^{\circ} \mathrm{C}\right)$. 


\section{Conclusions}

The grain growth activation energy of a Fe-Mn-Al-C steel was measured to be $467 \mathrm{~kJ} / \mathrm{mol}$. In comparison to previous works this activation energy for grain growth is reasonable when taking into account the alloy concentrations and the stacking fault energy, and it was further suggested that carbon increases the activation energy significantly in the temperature regime examined. The strength of the material is strongly correlated to the mean linear intercept (L3) from the Hall-Petch relationship, and it was shown that as the boundary spacing (grain and twin boundaries) is reduced the total ductility is also reduced. It can also be stated that as the grain size decreased the work hardening capacity moderately increased; a reduction of grain size from 200 to $30 \mu \mathrm{m}$ added $200 \mathrm{MPa}$ in the maximum work hardening capacity of the steel.

Author Contributions: Conceptualization, D.M.F. and K.R.L.; formal analysis, D.M.F.; investigation, D.M.F., K.R.L., and B.C.H.; writing — original draft preparation, D.M.F; writing—review and editing, K.R.L.

Funding: This research was funded in part by Congressional support through the Combat Vehicle Weight Reduction Initiative. D.F. was supported by a research appointment at the U.S. Army Combat Capabilities Development Command Army Research Laboratory accomplished under Cooperative Agreement Number W911NF-18-2-0046.

Acknowledgments: The authors would also like to thank Fred Fletcher at ArcelorMittal, Edward Horwath, Steven Marsh, and Mike Aniska for their assistance in this project.

Conflicts of Interest: The authors declare no conflict of interest. The views and conclusions contained in this document are those of the authors and should not be interpreted as representing the official policies, either expressed or implied, of the U.S. Army Combat Capabilities Development Command Army Research Laboratory or of the U.S. Government. 


\section{Appendix A}

Table A1. Hardness and grain size data utilized for the analysis of the current study.

\begin{tabular}{|c|c|c|c|c|c|c|c|c|c|c|c|c|c|c|c|c|}
\hline \multicolumn{2}{|c|}{ Temperature } & \multicolumn{3}{|c|}{$0.5 \mathrm{~h}$} & \multicolumn{3}{|c|}{$1 \mathrm{~h}$} & \multicolumn{3}{|c|}{$2 \mathrm{~h}$} & \multicolumn{3}{|c|}{$4 \mathrm{~h}$} & \multicolumn{3}{|c|}{$15 \mathrm{~h}$} \\
\hline $\mathrm{C}$ & $\mathbf{K}$ & $\mathrm{D} \mu \mathrm{m}$ & $1 / \sqrt{ } D$ & $\begin{array}{c}\text { Hardness } \\
\text { HBW }\end{array}$ & $\mathrm{D} \mu \mathrm{m}$ & $1 / \sqrt{ } D$ & $\begin{array}{c}\text { Hardness } \\
\text { HBW }\end{array}$ & $\mathrm{D} \mu \mathrm{m}$ & $1 / \sqrt{ } D$ & $\begin{array}{c}\text { Hardness } \\
\text { HBW }\end{array}$ & $\mathrm{D} \mu \mathrm{m}$ & $1 / \sqrt{ } D$ & $\begin{array}{c}\text { Hardness } \\
\text { HBW }\end{array}$ & $\mathrm{D} \mu \mathrm{m}$ & $1 / \sqrt{ } D$ & $\begin{array}{c}\text { Hardness } \\
\text { HBW }\end{array}$ \\
\hline 900 & 1173 & $32 \pm 4$ & 0.177 & $252 \pm 3$ & $29 \pm 2$ & 0.186 & $260 \pm 3$ & $30 \pm 2$ & 0.183 & $252 \pm 4$ & $34 \pm 2$ & 0.173 & $248 \pm 3$ & $35 \pm 1$ & 0.170 & $251 \pm 4$ \\
\hline 950 & 1223 & $34 \pm 2$ & 0.171 & $251 \pm 4$ & $31 \pm 4$ & 0.174 & $244 \pm 4$ & $57 \pm 8$ & 0.132 & $236 \pm 8$ & $51 \pm 3$ & 0.140 & $240 \pm 2$ & $81 \pm 6$ & 0.112 & $244 \pm 4$ \\
\hline 975 & 1248 & $47 \pm 5$ & 0.145 & $249 \pm 2$ & $45 \pm 6$ & 0.148 & $244 \pm 2$ & $82 \pm 3$ & 0.110 & $225 \pm 4$ & $75 \pm 5$ & 0.116 & $217 \pm 5$ & $68 \pm 2$ & 0.121 & $232 \pm 5$ \\
\hline 1000 & 1273 & $74 \pm 5$ & 0.116 & $227 \pm 1$ & $86 \pm 5$ & 0.108 & $226 \pm 3$ & $156 \pm 6$ & 0.080 & $218 \pm 8$ & $101 \pm 5$ & 0.100 & $217 \pm 3$ & $73 \pm 5$ & 0.117 & $227 \pm 4$ \\
\hline 1050 & 1323 & $116 \pm 8$ & 0.092 & $217 \pm 5$ & $160 \pm 6$ & 0.079 & $208 \pm 3$ & $201 \pm 8$ & 0.071 & $203 \pm 5$ & $250 \pm 2$ & 0.063 & $200 \pm 4$ & $161 \pm 8$ & 0.079 & $210 \pm 5$ \\
\hline 1075 & 1348 & $240 \pm 7$ & 0.064 & $205 \pm 4$ & $252 \pm 6$ & 0.063 & $200 \pm 2$ & $327 \pm 4$ & 0.055 & $201 \pm 7$ & $370 \pm 4$ & 0.052 & $192 \pm 4$ & $475 \pm 6$ & 0.046 & $195 \pm 5$ \\
\hline
\end{tabular}




\section{References}

1. Frommeyer, G.; Brüx, U. Microstructures and mechanical properties of high-strength Fe-Mn-Al-C high-weight TRI-PLEX steels. Steel Res. Int. 2006, 77, 627-633. [CrossRef]

2. Scott, C.; Alain, S.; Farral, M.; Tsuji, N.; Tanaka, Y. Austenitic steel for automotive application. Revue de Métallurgie 2006, 103, 293-302. [CrossRef]

3. Bartlett, L.; Van Aken, D.C. High Manganese and Aluminum Steels for the Military and Transportation Industry. JOM 2014, 66, 1770-1784. [CrossRef]

4. Hadfield, R.; Burnham, T.H. Special Steels, 2nd ed.; The Pitman Press: New York, NY, USA, 1933; p. 100.

5. Sevillano, J.G. An alternative model for the strain hardening of FCC alloys that twin, validated for twinning-induced plasticity steel. Scr. Mater. 2009, 60, 336-339. [CrossRef]

6. Lu, W.J.; Zhang, X.F.; Qin, R.S. K-carbide hardening in a low density high-Al high-Mn multiphase steel. Mater. Lett. 2015, 138, 96-99. [CrossRef]

7. Kalashnikov, I.S.; Acselrad, O.; Shalkevich, A.; Chumakova, L.D.; Pereira, L.C. Heat Treatment and Thermal Stability of FeMnAlC alloys. J. Mater. Process. Technol. 2003, 136, 72-79. [CrossRef]

8. Mazancova, E.; Ruziak, I.; Schindler, I. Influence of rolling condition and aging process on mechanical properties of high manganese steels. Arch. Civ. Mech. Eng. 2012, 12, 142-147. [CrossRef]

9. Field, D.M.; Qing, J.; Van Aken, D.C. Chemistry and properties of Medium-Mn Two-Stage TRIP steels. Metall. Meter. Trans. A 2019, 49, 4615-4632. [CrossRef]

10. Field, D.M.; Van Aken, D.C. Nanocrystalline Advanced High Strength Steel Produced by Cold Rolling and Annealing. Metall. Meter. Trans. A 2016, 47, 1912-1917.

11. Torabinejad, V.; Zarei-Hanzaki, A.; Moemeni, S.; Imandoust, A. An investigation to the microstructural evolution of Fe-29Mn-5Al dual-phase twinning induced plasticity steel through annealing. Mater. Des. 2011, 32, 5015-5021. [CrossRef]

12. Yuan, X.; Chen, L.; Zhao, Y.; Di, H.; Zhu, F. Influence of annealing temperature on mechanical properties and microstructure of a high manganese austenitic steel. J. Mater. Process. Technol. 2015, 217, 278-285. [CrossRef]

13. Yoo, J.D.; Huang, S.W.; Park, K.-T. Origin of Extended Tensile Ductility of a Fe-28Mn-10Al-1C Steel. Metall. Meter. Trans. A 2009, 40A, 1520-1523. [CrossRef]

14. Lee, S.I.; Lee, S.Y.; Han, J.; Hwang, B. Deformation behavior and tensile properties of an austenitic Fe-24Mn-4Cr-0.5C high manganese steel: Effect of grain size. Mater. Sci. Eng. A 2019, 742, 334-343. [CrossRef]

15. Field, D.M.; Van Aken, D.C. Dynamic Strain Aging Phenomena and Tensile Response of Medium-Mn TRIP Steel. Metall. Meter. Trans. A 2018, 49, 1152-1166. [CrossRef]

16. Field, D.M.; Limmer, K.R. Effect of Solution Treatment on Grain Size and Toughness of Lightweight Fe-Mn-Al-C Steel. In Proceedings of the AIST2019, Pittsburgh, PA, USA, 6-9 May 2019. [CrossRef]

17. Moon, J.; Park, S.-J.; Lee, C.; Han, H.N.; Lee, T.-H.; Lee, C.-H. Microstructure Evolution and Age-Hardening Behavior of a Micro-alloyed Austenitic Fe-30Mn-9Al-0.9C Light-Weight Steel. Metall. Meter. Trans. A 2017, 48A, 4500-4510. [CrossRef]

18. Yoo, J.D.; Hwang, S.W.; Park, K.T. Factors influencing the tensile behavior of a Fe-28Mn-9Al-0.8C Steel. Mater. Sci. Eng. A 2009, 508, 234-240. [CrossRef]

19. Bhattacharyya, M.; Langelier, B.; Purdy, G.R.; Zurob, H.S. Effect of Mn and C on Grain Growth in Mn Steels. Metall. Meter. Trans. A 2019, 50A, 905-914. [CrossRef]

20. Medvedeva, N.I.; Park, M.S.; Van Aken, D.C.; Medvedeva, J.E. First Principles study of Mn, Al, and C distribution and their effect on stacking fault energy in fcc Fe. J. Alloys Compd. 2014, 582, 475-482. [CrossRef]

21. Pisarik, S.T.; Van Aken, D.C. Thermodynamic Driving Force of the $\gamma \rightarrow \varepsilon$ Transformation and Resulting Ms temperature in High-Mn Steels. Metall. Meter. Trans. A 2016, 47, 1009-1018. [CrossRef]

22. Field, D.M.; Baker, D.S.; Van Aken, D.C. On the Prediction of $\alpha$-martensite Temperatures in Medium-Mn Steels. Metall. Meter. Trans. A 2017, 48, 2150-2163. [CrossRef]

23. Medvedeva, N.I.; Van Aken, D.C.; Medvedeva, J.E. Magnetism in bcc and fcc Fe with carbon and manganese. J. Phys. Condens. Matter. 2010, 22, 316002. [CrossRef] [PubMed]

24. ASTM E112-13 Standard Test Methods for Determining Average Grain Size; ASTM International: West Conshohocken, PA, USA, 2013. 
25. ASTM E18-17e1 Standard Test Methods for Rockwell Hardness of Metallic Materials; ASTM International: West Conshohocken, PA, USA, 2017.

26. ASTM E 8/E 8M-08, Standard Test Methods for Tension Testing of Metallic Materials; ASTM International: West Conshohocken, PA, USA, 2018.

27. Hillert, M. On the Theory of Normal Gain Growth. Acta Met. 1965, 13, 227-238. [CrossRef]

28. Burk, J.E.; Turnbull, D. Recrystallization and Grain Growth. Prog. Met. Phys. 1952, 3, 220-244. [CrossRef]

29. Cooke, B.A.; Jones, A.R.; Ralph, B. Recrystallization of microduplex steels. Met. Sci. 1979, 13, $179-186$. [CrossRef]

30. Ralph, B. Grain Boundaries in Engineering Materials. In Grain Boundary and Structure Kinetics, 1st ed.; ASM Intl.: Metal's Park, OH, USA, 1979; pp. 181-208.

31. Lücke, K.; Detert, K.A. Quantitative Theory of Grain-Boundary Motion and recrystallization in Metals in the presence of impurities. Acta Metall. 1957, 5, 628-637. [CrossRef]

32. Gordon, P.; Vandermeer, R.A. Mechanism of Boundary Migration in Recrystallization. Trans. Metall. Soc. AIME 1962, 224, 917-928.

33. Dastur, Y.N.; Leslie, W.C. Mechanism of Work Hardening in Hadfield manganese Steel. Metall. Trans. A 1981, 12, 749-759. [CrossRef]

34. Khzouz, E. Grain Growth Kinetics in Steel, Worcester Polytechnic Institute, Major Qualifying Project. Available online: https://web.wpi.edu/Pubs/E-project/Available/E-project-042211-104204/unrestricted/MQP_ -_Grain_Growth_Kinetics_in_Steels.pdf (accessed on 5 May 2019).

35. Lee, S.-J.; Lee, Y.-K. Prediction of austenite grain growth during austenitization of low alloy steels. Mater. Des. 2008, 29, 1840-1844. [CrossRef]

36. Kashyap, B.P.; Tangri, K. Grain Growth behaviour of type 316L stainless steel. Mater. Sci. Eng. A 1992, 149, L13-L16. [CrossRef]

37. Charnock, W.; Nutting, J. The Effect of Carbon and Nickel upon the Stacking-Fault Energy of Iron. Met. Sci. J. 1967, 1, 123-127. [CrossRef]

38. Feraiuolo, A.; Smithm, A.; Sevillano, J.G.; De las Cuevas, F.; Pratolongo, G.; Gouveia, H.; Mendes, M.; Karjalainen, P. Metallurgical design of high strength austenitic Fe-C-Mn steels with excellent formability. Metal. Des. 2006. [CrossRef] 